\title{
Naturalistic Observations of Nonverbal Children with Autism: A Study of Intentional Communicative Acts in the Classroom
}

\author{
Samantha Drain ${ }^{1}$ and Paul E. Engelhardt ${ }^{2}$ \\ ${ }^{1}$ Department of Psychology, University of Chester, Parkgate Road, Chester CH1 4BJ, UK \\ ${ }^{2}$ School of Psychology, University of East Anglia, Norwich Research Park, Elizabeth Fry Building 1.10, Norwich NR4 7TJ, UK \\ Correspondence should be addressed to Paul E. Engelhardt; p.engelhardt@uea.ac.uk
}

Received 20 March 2013; Revised 9 June 2013; Accepted 11 June 2013

Academic Editor: Cheryl Dissanayake

Copyright (c) 2013 S. Drain and P. E. Engelhardt. This is an open access article distributed under the Creative Commons Attribution License, which permits unrestricted use, distribution, and reproduction in any medium, provided the original work is properly cited.

\begin{abstract}
We examined evoked and spontaneous communicative acts in six nonverbal children with autism (10-15 years, $\mathrm{M}=12.8, \mathrm{SD}=$ 2.1). All participants attended the same special school for children with autism but were in different classes. Each was observed for 30 minutes during a typical school day. An observer coded the presence/absence of an antecedent, the form and function of the communicative act, and the teacher's response to the child. One hundred and fifty-five communicative acts were observed, $41 \%$ were spontaneous and 59\% were evoked. The main antecedents to evoked communicative acts were verbal prompts, and most of the evoked communicative acts were physical in nature (i.e., motor acts and gestures). However, verbalizations and the use of the Picture Exchange Communication System (PECS) were higher for spontaneous communicative acts. The functions of spontaneous communicative acts were primarily requests. Results showed a substantial number of "nonresponses" from teachers, even following evoked communicative acts. These results suggest that teachers may not actively promote intentional communication as much as possible. Therefore, our findings provide information concerning ways in which educators could facilitate intentional communication in non-verbal children with autism.
\end{abstract}

\section{Introduction}

Autism is a neurodevelopmental disorder that is characterized by impairments in social, behavioral, and linguistic domains. The DSM-IV diagnostic criteria for autism are based on substantial impairments in communication and social interactions [1]. By some estimates, $25 \%$ of individuals with autism do not develop speech [2-4]. In addition, they also tend to show restrictive, repetitive, and stereotyped behaviors. However, it is important to note that most children with autism do use intentional communication even if they do not have symbolic communication abilities [5-8]. Stone et al. [9] reported that most nonverbal children with autism use less complex behaviors in their communicative acts compared to typically developing children, who use language as their primary means of communication. For example, if a child with autism wants an object, they will simply reach for it or make gesture, such as pointing, to indicate what they want. Similarly, in other cases, children with autism may use eye gaze or unusual verbalizations $[10,11]$, whereas a typically developing child will employ language to express their wants/desires. In general, there has been little systematic research on intentional communicative acts in nonverbal children with autism (cf. $[5,12-14]$ ), and so, there is a need for research that examines the relationships between the antecedent of a communicative act, the form and function of the communicative act, and the response provided by a teacher to the child. In the current study, we examined both spontaneous and evoked communicative acts in nonverbal children with autism in a naturalistic (classroom) environment.

In order to improve communication, augmentative and alternative communication systems have been used to support children with autism [15-18]. There are two main types. Unaided systems refer to communication systems that do not have external devices; that is, they rely on motor actions and manual signs. Aided systems have external devices, such as communication boards or the Picture Exchange Communication System (PECS) [19-21]. The goal of both types of systems is to encourage children with autism to gain 
and use functional communication skills in interactive social situations. PECS has been argued to be one of the best aided systems because it tends to promote more spontaneous communicative acts, which is one of the main weaknesses in autism [22-30]. With PECS, children are encouraged and/or taught to approach a communicative partner and gain their attention by placing one of the cards in their hand. Therefore, PECS may encourage individuals with autism to communicate with other people in a more spontaneous manner [31].

Boucher and Lewis [22] argued that children with autism may not be impaired in their ability to communicate but rather that they have a deficit with regards to the spontaneity of social interactions (see also [32]). Thus, children with autism do not always display communication behaviors that they in fact have the ability to perform. Kanner [28] also noted an absence of spontaneous sentence production in children with autism who did have symbolic communication as well as those who had more limited language abilities (see also $[23,33,34])$. Spontaneous communication is important for several reasons [32, 35-37]. First, it allows a person to initiate social interactions. Second, it gives a person some control over their environment, and what they do. Third, it allows a person to convey their personal needs to others. If a person is solely reliant upon their partners' cues, then their ability to communicate will be severely restricted. Preliminary research suggests that the more children with autism respond spontaneously to natural stimuli, the more their behavior resembles that of typically developing children [35]. Spontaneity, then, appears to be a significant factor affecting children's ability to effectively communicate, and, thus, to successfully employ intentional communication.

The issue of spontaneity in communication has been operationalized in two ways (for reviews, see $[25,38]$ ). The first way views spontaneity as a binary, which essentially is all or nothing. If there is an antecedent to the communicative act, then it is not spontaneous. In contrast, if there is no antecedent, then the communicative act is spontaneous. The second view sees spontaneity as occurring along a continuum $[27,39]$. According to this conceptualization, all communicative acts have some degree of spontaneity, and the level is dependent upon the extent to which the evoking stimulus is related to the communicative act.

Carter and Hotchkins [38] devised a four-level antecedent model with regards to expressive communicative acts. The goal of their model was to provide a scheme for classifying antecedents, which then permits a closer examination of the spontaneity of a communicative act. This model has been reliable across a number of studies $[24,25,40]$. The antecedent category that is the most spontaneous is a natural cue (i.e., the mere presence of a desired object or communicative partner) (We refer to intentional communicative acts in response to naturalistic cues as spontaneous. All other antecedent types are associated with evoked communication.) The second category along the continuum is stimulus highlighting, which focuses on prompts that actively draw attention to an object (or a person), thereby altering the saliency of an entity in the environment. The third category is generalized communicative cues. These are cues that require a response but do not directly indicate what that response is (e.g., verbal prompts, such as "tell me what you want" or presenting several PECS cards). The fourth category, direct prompts, is deemed the least spontaneous. This type of antecedent requires a specific response (e.g., an instruction to perform an action). In the current study, we used this categorical (continuum) approach because it allowed us to investigate a range of antecedents and to more systematically study which antecedents evoked communicative acts from children with autism.

There have been four studies that investigated expressive communication by observing children with autism in a classroom setting [5, 12-14]. Stone and Caro-Martinez [14] focused on spontaneous communicative acts, which occurred on average 3-4 times per hour in their study. They found that the form of the communicative acts consisted of 52\% motor acts, $26 \%$ speech acts, $16 \%$ vocalizations, and $13 \%$ gestures. (Motor acts were defined as physical communications that were nonsymbolic in nature, and gestures were symbolic.) The functions of the communicative acts were getting attention $(23 \%)$, engaging in social routine $(22 \%)$, requesting things (22\%), commenting (15\%), and rejecting things (8\%). In a similar study that compared children with autism across two countries (i.e., Australia and Taiwan), Chiang and Lin [5] investigated expressive communicative acts in children with a range of verbal abilities. The purpose of the study was to examine how many children, from the sample of 32, used different forms of communication (i.e., aided communication systems, unaided communication systems, or speech), as well as the functions of their communicative acts (i.e., commenting, requesting, or rejecting). Results showed that children on average produced 44 communicative acts per hour. Unaided communicative acts were more frequent than both aided communication and speech. With regard to functions, requesting and commenting were used (significantly) more frequently compared to rejecting.

The final study was conducted by Chiang [13], and she focused primarily on the form and function of spontaneous and evoked communicative events. Results showed that spontaneous communicative acts were significantly more common than evoked communicative acts. The form of the communicative acts showed greater frequency of unaided communication and speech, and both were more frequent than aided communication. Unaided communicating was significantly higher than speech for spontaneous communicative acts, but there was no difference between the two for evoked communicative acts. The "functions" of the communicative acts showed an interaction. Requesting was higher than commenting for spontaneous and the pattern was reversed for evoked, (i.e., commenting > requesting). Partner responses were also analyzed in this particular study. The most common response to the child was to acknowledge their communication, and this held for both spontaneous and evoked communicative acts. Deny responses (i.e., verbally and/or physically refusing the child's request) and deliver responses (i.e., giving the requested object/activity to the child) were more common for spontaneous communicative acts compared to evoked communicative acts. In addition, there was a trend for more "nonresponses" with the spontaneous communicative acts. 
There are a couple of limitations in these studies. First, none examined the full range of antecedents (i.e., naturalistic cues, generalized cues, stimulus highlighting, and direct prompts), and none examined the relationship between the antecedent type and spontaneous versus evoked communicative acts. To date, there has been only a single study (i.e., [13]) that examined the ratio of evoked compared to spontaneous communicative acts within the same individuals. Second, there was a great deal of variability in where the observations occurred. In Chiang's studies, some participants were observed in special schools, some in regular schools, and some in their homes. There is an additional issue in that observations within the school environment took place during quite disparate activities and/or locations (e.g. "normal" academic activities, free time, physical education, cafeteria, hallways, etc.). To our knowledge, the length of time that participants spent in the different activities was not controlled, and, thus, the mean communication rates may not truly reflect communication tendencies in the classroom. It is assumed that home observations consisted mainly of interactions with parents, which would presumably have higher communication rates compared to teacher interactions in the classroom [41, 42].

In summary, there is preliminary evidence that relationships may exist between the type of antecedent and the form and function of expressive communication that children with autism produce. We were also interested in the teacher's responses to the children and whether these differed depending on evoked or spontaneous communicative acts. As mentioned previously, there has been only a single study that has investigated spontaneous and evoked communication in children with autism [13], and, to a large extent, there has been little research on expressive communicative acts in nonverbal children with autism, despite the fact that research suggests that approximately $25 \%$ of children with autism are nonverbal [2-4]. Therefore, the primary purpose of the study was to add to the literature on intentional communicative acts in nonverbal children with autism in a classroom environment. Our specific research questions were (1) what are the most successful antecedents in evoking intentional communicative acts? (2) what are the most common forms of communicative acts used by children with autism? (3) what are the functions of those communicative acts? and (4) how do teachers respond to the intentional communicative acts made by children with autism?

\section{Method}

2.1. Participants. Six children with autism participated in the study, ranging in age from 10 to $15 \mathrm{yrs}(\mathrm{M}=12.8, \mathrm{SD}=$ 2.1). Participants were recruited through the North East Autism Society. All children had severe language impairments (i.e., fewer than five functional words) and had been diagnosed with autism by a physician or psychiatrist. Standardized assessments of language and cognitive abilities, adaptive behavior, and autism symptom severity were not available to the research team. In addition, the research team was not provided with information concerning how much the use of PECS is emphasized within classroom instruction in this particular school.

2.2. Materials. A coding sheet was used to record the spontaneous and evoked communicative acts made by the children $[12,38]$. The coding sheet was divided into four main categories: the antecedent, the child's response, the function of the communicative act and the teacher's response to the child. The sheet also had a section at the bottom that allowed the observer to make notes regarding the situation, and the time the observation started and ended. The frequencies of events within each category were summed for each participant and then transformed into proportions for each child. The analyses were carried out on the proportions.

2.3. Design and Procedure. All observations were carried out in the same school, which was a special school for children with autism, located in the northeast of England. The children who were observed were permanently located in different classes from one another. However, there were three or four other children with autism or other developmental disabilities in each of the classrooms and one teacher and two teaching assistants. The observations took place over five days at various times throughout the day, and each observation took place during a structured teacher-led activity. Each child was observed in a single 30-minute session during their regular school routine. The teachers and teaching assistants were blind to the purposes of the study and were asked to maintain their normal activities. The observer was an undergraduate psychology student who was trained on the forms of communicative acts and the coding scheme used in the study. In order to assess observer reliability, we had the observer and a second trained researcher code several short videos of a nonverbal child with autism interacting with a parent or a teacher. The proportion of agreement between the two raters ranged from 1.0 for the form of the child's communicative act to .94 for the teacher/parent's response to the child. In addition, the primary observer (i.e., the first author) had extensive experience (approximately 20 hours per week over 2 years) working with children with autism in a residential care setting.

2.4. Communication Coding. A communicative act was considered expressive if there was evidence that the child was actively communicating information to a teacher (or a teachers' assistant). If the child merely complied with an instruction or request from the teacher, it was not coded as an intentional communicative act [5]. In contrast, if the child's behavior was a response to the teacher's question (e.g., "What do you want?"), then it was coded as an intentional communicative act.

Due to the limited sample size, we analyzed our data using nonparametric tests, which do not rely on the assumption of normality and are substantially more conservative than parametric tests. For analyses that compared three or more variables, we used a Friedman test, which is conceptually similar to a one-way repeated measures ANOVA. However, the test of significance is chi-square $\left(\chi^{2}\right)$ instead of $F$-ratio. For analyses 
that compared two variables, we used a Wilcoxon signedrank test, which is conceptually similar to a paired samples $t$ test. All analyses were two tailed. Evoked communicative acts were analyzed with a Friedman test coded along a continuum with three categories: (1) stimulus highlighting (e.g., teacher comments that drew attention to an object), (2) generalized communicative cues, indicating that a nonspecific response was required (e.g., questions and the presentation of PECS cards), and (3) direct prompts, indicating that a specific response was required [38]. The category direct prompts was subdivided into four categories: verbal (e.g., questions or instructions), modeling (e.g., demonstrating a requested response), physical (e.g., giving assistance), and other. (Other responses were infrequent and excluded from the analysis.) If more than one form of prompting occurred simultaneously or in rapid succession, then all forms were coded. However, this almost never occurred during any of the observations.

A Friedman test was also used to analyze the communication forms employed by the children. Separate tests were conducted for both evoked and spontaneous communicative acts. Response types were verbal (e.g., echolalic or other verbal sound), physical (e.g., gestures and sign language), use of PECS (e.g., the child employed PECS successfully), modeling (e.g., the child copied the teachers prompting), challenging behavior (e.g., self-harm, tantrums, and physical violence), and other. (Challenging behavior and "other" turned out to be infrequent and were excluded from the analyses.)

A Friedman test was used to examine the functions of the communicative acts produced, and, again, the evoked and spontaneous communicative acts were examined separately. Functions were coded as a request (e.g., asking for an object), reject (e.g., refuse to accept an object or instruction), and other (e.g., greeting another person, commenting on an object, etc.).

Finally, a Friedman test was used to examine the responses that the teacher (or teachers' assistant) made to the child. (Participants never communicated with other children in the classroom.) For both evoked and spontaneous communicative acts, teachers' responses were coded into six categories: deny (i.e., the teacher verbally and/or physically refused the child's request), acknowledge (i.e., the teacher verbally acknowledged the child), no response (i.e., no verbal/physical reaction to the child), delivered (i.e., the referent was given to the child), removed (i.e. the referent that the child wanted or disliked was removed), and other. (The acknowledge category was used only for those instances in which the teacher acknowledged the communication but did not act on it further (i.e., deny, deliver, and remove).) (Again, "removed" and "other" responses were very infrequent and so, were excluded from the analyses.)

\section{Results}

Results showed that 63 of the 155 communicative events were spontaneous. The other 92 were evoked from generalized cues, stimulus highlighting, and direct prompts. A Wilcoxon test showed no difference between spontaneous and evoked communicative acts $z=-1.15, P=.25$.
3.1. Antecedents. The first Friedman test revealed a significant difference between direct prompts, stimulus highlighting, and generalized prompts $\chi^{2}(2)=11.56, P=.003$ (see Figure 1(a)). (For this analysis the direct prompts were summed.) The Wilcoxon paired comparisons revealed significant differences between generalized and direct prompts $z=$ $-2.20, P=.028$, stimulus highlighting and direct prompts $z=$ $-2.20, P=.028$, and stimulus highlighting and generalized $z=-2.02, P=.043$. Table 1 shows the frequency counts for each participant separately. A second Friedman test revealed that there was a significant difference in the types of direct prompts used by the teacher to evoke intentional communicative acts $\chi^{2}(2)=6.91, P=.032$ (see four bars on the right side of Figure 1(a)). Wilcoxon paired comparisons were conducted to examine the differences between the different categories. Results showed a significant difference between verbal and physical prompts $z=-2.20, P=.028$. This shows that verbal prompts were the most effective direct prompt for evoking communicative acts from children. There were no significant differences for any of the other paired comparisons (all $P^{\prime}$ s $>.05$ ).

3.2. Child's Communication. A Friedman test conducted on evoked communicative acts revealed a significant effect $\chi^{2}(3)=10.44, P=.015$. The proportions are shown on the left side of Figure 1(b). There were significant (paired) comparisons between verbal and physical responses $z=$ $-2.20, P=.028$, between PECS and physical responses $z=-2.20, P=.028$, and between physical responses and modeling $z=-1.99, P=.046$. None of the other paired comparisons were significant (all $P$ 's $>.05$ ). For spontaneous communicative acts, the Friedman test was not significant $\chi^{2}(3)=5.59, P=.133$. Thus, physical communication acts were the most common response for evoked communicative acts and a similar (but not significant) trend was observed for spontaneous communicative acts.

3.3. Function of Communication. A Friedman test conducted on evoked communicative acts revealed a significant effect $\chi^{2}(2)=10.57, P=.005$ (see Figure 1(c) and Table 2 for frequency counts for each participant). Paired Wilcoxon comparisons indicated a significant difference between "other" and requests $z=-2.20, P=.028$ and "other" and rejects $z=-2.02, P=.043$. None of the other paired comparisons were significant. For spontaneous communicative acts, the Friedman test was also significant $\chi^{2}(2)=10.17, P=.006$. There were two significant paired comparisons. Requests were more common compared to rejects $z=-2.20, P=.028$, and requests were more frequent than other $z=-2.20$, $P=.028$. The difference between reject and other was not significant.

3.4. Teacher's Response. A Friedman test conducted on evoked communicative acts revealed a significant effect $\chi^{2}(3)=13.18, P=.004$ (see Figure $1(\mathrm{~d})$ ). Paired Wilcoxon tests revealed significant differences between acknowledge and deny responses $z=-2.20, P=.028$, no responses and 
TABLE 1: Frequency counts for both communication prompts and the form of communicative acts for each participant.

\begin{tabular}{|c|c|c|c|c|c|c|}
\hline & Part. 1 & Part. 2 & Part. 3 & Part. 4 & Part. 5 & Part. 6 \\
\hline \multicolumn{7}{|l|}{ Prompts } \\
\hline Naturalistic (spontaneous) & 15 & 14 & 11 & 3 & 5 & 15 \\
\hline Evoked & 27 & 7 & 17 & 17 & 8 & 16 \\
\hline Generalized & 4 & 1 & 3 & 3 & 1 & 5 \\
\hline Highlighting & 4 & 0 & 0 & 0 & 0 & 2 \\
\hline Verbal & 11 & 4 & 14 & 5 & 6 & 5 \\
\hline Modelling & 6 & 0 & 0 & 8 & 0 & 0 \\
\hline Physical & 2 & 2 & 0 & 0 & 0 & 3 \\
\hline \multicolumn{7}{|l|}{ Child's communication } \\
\hline Evoked & 27 & 7 & 17 & 17 & 8 & 16 \\
\hline PECS & 1 & 0 & 0 & 0 & 1 & 2 \\
\hline Verbal & 0 & 0 & 4 & 0 & 0 & 0 \\
\hline Modeling & 5 & 0 & 0 & 12 & 0 & 0 \\
\hline Physical & 21 & 7 & 9 & 4 & 6 & 14 \\
\hline Spontaneous & 15 & 14 & 11 & 3 & 5 & 15 \\
\hline PECS & 4 & 0 & 0 & 0 & 2 & 4 \\
\hline Verbal & 0 & 0 & 7 & 2 & 0 & 0 \\
\hline Modeling & 0 & 0 & 0 & 1 & 0 & 0 \\
\hline Physical & 11 & 14 & 4 & 0 & 3 & 8 \\
\hline
\end{tabular}

Note. PECS stands for picture exchange communication system. Part.: participant.

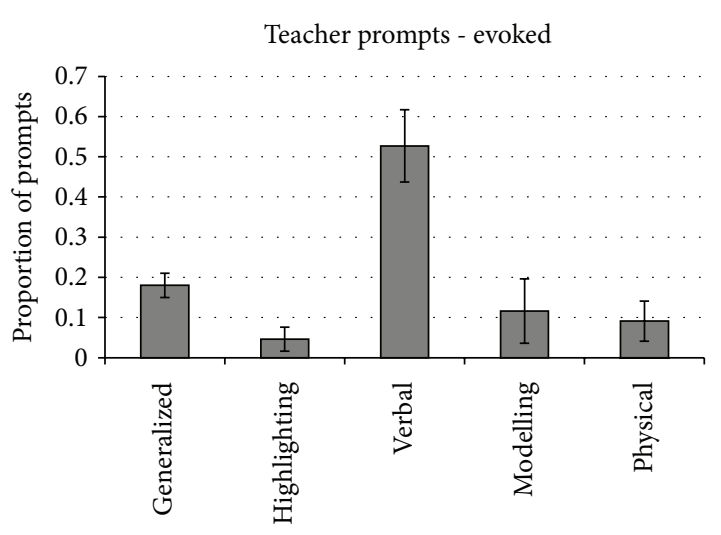

(a)

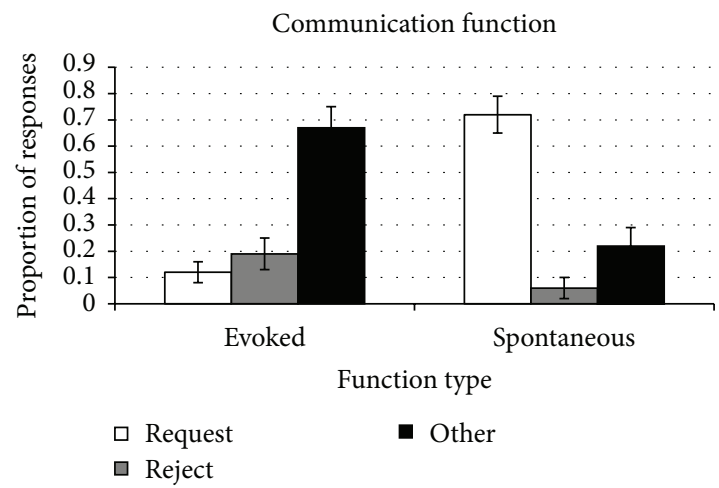

(c)

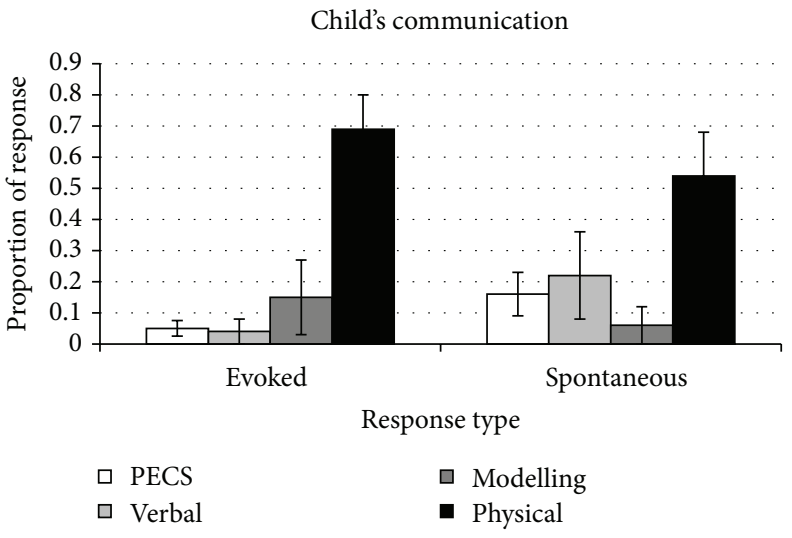

(b)

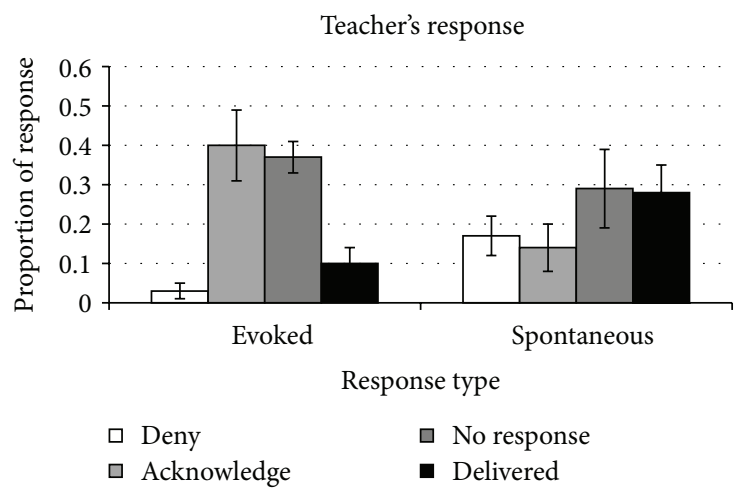

(d)

FIGURE 1: (a) shows the antecedents of evoked communicative acts. (b) shows the form of the communicative acts. (c) shows the function of the communicative acts. (d) shows the teacher's response to the child. Error bars show the standard error of the mean. 
TABLE 2: Frequency counts for both communication function and the teacher response for each participant.

\begin{tabular}{|c|c|c|c|c|c|c|}
\hline & Part. 1 & Part. 2 & Part. 3 & Part. 4 & Part. 5 & Part. 6 \\
\hline \multicolumn{7}{|c|}{ Communication function } \\
\hline Evoked & 27 & 7 & 17 & 17 & 8 & 16 \\
\hline Request & 3 & 0 & 4 & 1 & 2 & 1 \\
\hline Reject & 3 & 0 & 5 & 2 & 3 & 4 \\
\hline Other & 21 & 6 & 8 & 14 & 3 & 11 \\
\hline Spontaneous & 15 & 14 & 11 & 3 & 5 & 15 \\
\hline Request & 8 & 9 & 8 & 3 & 4 & 9 \\
\hline Reject & 0 & 0 & 1 & 0 & 0 & 4 \\
\hline Other & 7 & 5 & 2 & 0 & 1 & 2 \\
\hline \multicolumn{7}{|l|}{ Teacher response } \\
\hline Evoked & 27 & 7 & 17 & 17 & 8 & 16 \\
\hline Deny & 0 & 0 & 1 & 0 & 0 & 2 \\
\hline Acknowledge & 11 & 5 & 4 & 9 & 1 & 6 \\
\hline No response & 8 & 2 & 9 & 6 & 3 & 6 \\
\hline Delivered & 6 & 0 & 1 & 0 & 2 & 1 \\
\hline Spontaneous & 15 & 14 & 11 & 3 & 5 & 15 \\
\hline Deny & 3 & 3 & 2 & 1 & 0 & 1 \\
\hline Acknowledge & 2 & 2 & 1 & 0 & 2 & 1 \\
\hline No response & 1 & 5 & 7 & 0 & 2 & 4 \\
\hline Delivered & 7 & 2 & 1 & 1 & 1 & 7 \\
\hline
\end{tabular}

Notes. Part.: participant.

deny $z=-2.20, P=.028$, deliver and acknowledge $z=-1.99$, $P=.046$, and no responses and deliver $z=-2.20, P=.028$. For spontaneous communicative acts, the Friedman test was significant $\chi^{2}(3)=9.75, P=.02$, but none of the paired comparisons achieved significance. The most common response to evoked communicative acts was acknowledgement and non-response. The most common response to spontaneous communicative acts was non-response and delivered, but these effects were not statistically significant.

\section{Discussion}

The primary goal of this study was to investigate the intentional communicative acts of nonverbal children with autism in a classroom environment, and we were particularly interested in the differences between spontaneous and evoked communicative acts. The results showed that every child displayed intentional communication, despite their lack of symbolic communication. We investigated four main research questions, each of which focused on a different aspect of the communicative acts. The first question looked at what are the most successful antecedents in evoking expressive communication. Results showed, similar to Chiang [12], that verbal prompts were the most common antecedents. The second and third research questions looked at the form and function of the communicative acts displayed by the children, respectively. The final research question looked at the teacher's responses to the child. Overall, the children in this study showed somewhat higher rates of intentional communication compared to earlier work (51 per hour in the current study versus 44 per hour in Chiang and Lin's study). (Stone and
Caro-Martinez [14] focused on spontaneous communicative acts and they reported only 3-4 communicative acts per hour in their study.) Chiang [12] focused only on evoked communication from teacher instructions, and she reported a rate of ten per hour. As discussed in Section 1, we used a continuum approach with regard to antecedents, and we distinguished between evoked and spontaneous communicative acts.

This study found that $41 \%$ of the communicative acts were spontaneous. Chiang [13] also reported a high percentage of spontaneous communicative acts, and, in fact, spontaneous communicative acts were more common than evoked communicative acts in her study. There are two points that should be made concerning the rates of spontaneous communication that we observed. First, the spontaneous communicative acts were primarily instances in which the child wanted something (see also [13]). Thus, communication was driven by an internal desire for some object [20]. Second, the school in which the observations occurred does not adhere to highly structured teaching methods. Preliminary evidence indicates that structured teaching methods are successful in improving working skills and functional communication abilities of children with autism and other types of developmental disorders [43]. In contrast, Chiang and Carter [25] argued that structured teaching methods may stifle communicative spontaneity. Our data do not directly support this conjecture. However, given that the classroom environment in which the observations occurred was less structured, and when combined with the (relatively) high rates of spontaneous communication (i.e., 21 per hour), our data at least indirectly suggest that less-structured environments result in more spontaneous communicative acts. 
If this conjecture is true, it would provide important information for educators on how to facilitate and encourage more spontaneous communication. Of course, there would likely be a tradeoff in that less structure would presumably come at the cost of less learning. That is, minimizing the structure within the classroom environment may adversely affect the development of the children's working skills and other forms of learning. Thus, it may be that an equal balance of structured and nonstructured activities needs to be integrated into daily school timetables. A further point worth considering is whether the frequency and duration of unstructured activities should be dependent upon the child's current ability to communicate spontaneously. For example, if a child with autism demonstrates limited ability to spontaneously communicate, it may be beneficial for the child to develop their spontaneous communication skills compared to other alternative working skills (e.g., drawing or painting). The National Research Council [44] stated that the development of functional spontaneous communication is the most important goal in educating children with autism. However, these issues can only be speculated on at this time and are beyond the scope of the current investigation.

With regards to the second research question, we found that physical forms of communication were the most frequent, which is in line with the results from Chiang [13]. This finding is also consistent with other studies, in that children with autism, who are nonverbal, showed a preference for less complex communication forms, for example, physical gestures and modeling $[9,11]$. Often the signals that children with autism provide are idiosyncratic and subtle [45]; thus, in some instances, educators may miss communication signals displayed by the children. In addition throughout this study PECS was not frequently used by the children. However, we do not know how much or how often the teachers in this particular school actively promote the use of such devices. On the other hand, the severity of symptoms in these particular children may prevent them from using more complex forms of communication, such as PECS, and sign language, functional spoken language. We did find that the frequency of PECS was slightly higher when the child produced spontaneous communicative acts compared to evoked communicative acts. Thus, our data would suggest that children with autism are more likely to use PECS when requesting an object they want. Recall that the primary function of spontaneous communicative acts was requests for objects (i.e., > 70\%). On the other hand, children with autism may have a tendency (or preference) for communicating with their teachers using physical communicative acts, such as physical gestures and/or actions. Our data does not provide a base rate for physical versus PECS, and, so, we cannot determine what causes the differences we observed. Further research is needed in order to determine whether the use of PECS increases when the child is requesting something they want or whether the rate decreases because the teacher is attempting to get the child to comply with educational instructions.

The teacher's responses followed straightforwardly from the trends in the functions of the communicative acts. The spontaneous acts were responded to more frequently by denying and delivering the requested object compared to the evoked communicative acts. In contrast, when the teacher evoked the communication, their responses were more frequently to acknowledge the communication. Acknowledging and commending communicative behavior is one way of enacting a positive change in communication abilities in autism [46-48]. There was no difference in the rates of nonresponding by the teacher depending on whether the communication was evoked or spontaneous. However, about one-third of the communicative acts displayed by the children in this study did not evoke a response from the teacher (cf. [13]).

There are several potential reasons for this finding. First, the communicative behaviors of children with autism are often subtle and may be missed. Second, in the classroom setting, teachers have plans and goals for each lesson. Thus, in many instances, the goals of the teacher and the goals of the student conflict with one another, and nonresponses by the teacher may be cases in which the child's communicative act is not relevant to what the teacher is attempting to accomplish. This explanation is more likely following spontaneous, as opposed to evoked communicative acts. Related to this point, we found that challenging behavior was relatively infrequent [49-52]. Some have argued that challenging behavior is a form of communication in which the child is deliberately seeking attention [53], as well as to escape demands and gain access to objects and/or activities [52]. In either case, challenging behavior was infrequent in our observations.

4.1. Educational Implications. It is important to note that the results obtained from this study should be considered preliminary, due to the restricted sample size and observerreliability limitations. However, we believe that this study has several implications for educational practices for children with autism. The first is that our study supports previous research and provides clear examples that children with autism do communicate spontaneously, and they are more likely to do so when they want something [13]. Even though this study only had six participants, it provides empirical support for several teaching methods that are commonly used with nonverbal children with autism (e.g., making objects inaccessible, the Mand technique). The second point is also related to spontaneous communicative acts. We found somewhat higher rates of PECS use and more verbal communications when the children were communicating spontaneously. Thus, placing desired objects away from the child and having them communicate what they want should tend to evoke more desirable communicative behaviors [54-57]. This strategy is commonly employed in early interventions but may not be appropriate for school-aged pupils with autism. A further suggestion with regards to spontaneous communicative acts is for schools to incorporate more frequent unstructured activity sessions. The duration and frequency of such sessions could be altered depending on the ability of the pupils within the class to spontaneously communicate.

A final point concerns the rate of nonresponses by the teacher. There were a few instances of challenging behavior, and in the majority of these, the teacher did not respond. 
However, the vast majority of non-responses did not follow challenging behavior. As mentioned above, there may be good reasons why the teacher did not respond to the child in certain situations. In this study, we cannot say whether teacher non-responses had a positive or negative effect on communication development. Keen et al. [46] argued that the best practice for nonverbal children with autism is to provide frequent and consistent responses, and that this is the best way to facilitate and improve communication development $[58,59]$. Our data suggest that there is room for improvement in providing consistent feedback, at least for the teaching method/environment that we observed in.

4.2. Limitations and Future Directions. Several limitations need to be highlighted. First, we acknowledge that this study observed participants for a shorter period of time compared to previous studies (e.g., [5]), and of course, we recommend replication with a larger sample in order to ensure generalizability of the results. A larger sample would also obviate concerns about the statistical assumptions and permit the use of more standard parametric analyses. The second limitation was that there was no reliability check on the actual data. There were a couple of reasons why this was not possible; however, we did have two individuals independently code secondary data in order to ensure some level of reliability on the observations. We admit that this situation is less than ideal, and, again, we would encourage replication with a larger sample and reliability checks on the actual observations. The third limitation is that the activities that the child engaged in during the observation period were not always consistent. It is possible that certain classroom activities may have encouraged more communicative acts compared to others. However, all observations in this study took place in the classroom, and so, our data was collected in a more consistent environment compared to earlier work $[5,12-14]$. The final limitation is that we did not have developmental assessments (e.g., language and cognitive measures, autism symptom severity, etc.) for the participants in the study. Thus, we were not able to assess differences between individuals and their communicative tendencies.

We think that one important avenue for future work is to investigate whether communicative behaviors differ in the home, as compared to the school environment. In particular, the home and school differ in the number of structured activities, and so, it would be interesting to investigate how unstructured activities affect communicative behavior across settings.

\section{Conclusions}

The children in this study all showed intentional communication, and we found that the most successful antecedents for evoking intentional communication were verbal prompts and naturalistic cues. The most common intentional communicative acts were physical. They accounted for approximately one-third of all communicative acts in this study. However, we also found that with spontaneous communication (i.e., those due to naturalistic cues), the use of PECS increased compared to the use of PECS in evoked communication. The spontaneous communicative acts were primarily requests for objects [13]. Finally, a substantial percentage of intentional communicative acts resulted in a nonresponse from the teacher. Future work will need to be conducted to determine whether nonresponses in certain situations (e.g., following challenging behavior) have positive or negative effects on communication development. In summary, this study largely supports previous research with respect to the form and function of spontaneous and evoked communication. However, it also extends existing literature by examining the antecedents to the intentional communicative acts.

\section{Acknowledgments}

The authors would like to thank Sean N. Veld and Kerry Shields for help with data analysis and for constructive discussions of the findings. They would also like to thank the Northeast Autism Society and Margaret Burton for arranging the observation sessions.

\section{References}

[1] American Psychiatric Association, Diagnostic and Statistical Manual of Mental Disorders, American Psychiatric Association, Washington, DC, USA, 4th edition, 2000.

[2] E. Fombonne, "The epidemiology of autism: a review," Psychological Medicine, vol. 29, no. 4, pp. 769-786, 1999.

[3] C. Lord, S. Risi, and A. Pickles, "Trajectory of language development in autistic spectrum disorders," in Developmental Language Disorders: From Phenotypes to Etiologies, M. L. Rice and S. F. Warren, Eds., pp. 7-29, Lawrence Erlbaum Associates, Mahwah, NJ, USA, 2004.

[4] F. R. Volkmar, C. Lord, A. Bailey, R. T. Schultz, and A. Klin, "Autism and pervasive developmental disorders," Journal of Child Psychology and Psychiatry and Allied Disciplines, vol. 45, no. 1, pp. 135-170, 2004.

[5] H.-M. Chiang and Y.-H. Lin, "Expressive communication of children with autism," Journal of Autism and Developmental Disorders, vol. 38, no. 3, pp. 538-545, 2008.

[6] A. S. Chan, J. Cheung, W. W. M. Leung, R. Cheung, and M. Cheung, "Verbal expression and comprehension deficits in young children with autism," Focus on Autism and Other Developmental Disabilities, vol. 20, pp. 117-124, 2005.

[7] S. Mitchell, J. Brian, L. Zwaigenbaum et al., "Early language and communication development of infants later diagnosed with autism spectrum disorder," Journal of Developmental and Behavioral Pediatrics, vol. 27, no. 2, pp. S69-S78, 2006.

[8] A. M. Wetherby, "Ontogeny of communicative functions in autism," Journal of Autism and Developmental Disorders, vol. 16, no. 3, pp. 295-316, 1986.

[9] W. L. Stone, O. Y. Ousley, P. J. Yoder, K. L. Hogan, and S. L. Hepburn, "Nonverbal communication in two- and three-yearold children with autism," Journal of Autism and Developmental Disorders, vol. 27, no. 6, pp. 677-696, 1997.

[10] R. Paul, "Assessing communication in autism spectrum disorders," in Handbook of Autism and Pervasive Developmental Disorders, F. R. Volkmar, R. Paul, A. Klin, and D. Cohen, Eds., vol. 2, pp. 799-816, John Wiley \& Sons, Hoboken, NJ, USA, 2005.

[11] P. Yoder, R. B. McCathren, S. F. Warren, and A. L. Watson, "Important distinctions in measuring maternal responses 
to communication in prelinguistic children with disabilities," Communication Disorder Quarterly, vol. 22, pp. 135-147, 2001.

[12] H.-M. Chiang, "Naturalistic observations of elicited expressive communication of children with autism: an analysis of teacher instructions," Autism, vol. 13, no. 2, pp. 165-178, 2009.

[13] H.-M. Chiang, "Differences between spontaneous and elicited expressive communication in children with autism," Research in Autism Spectrum Disorders, vol. 3, no. 1, pp. 214-222, 2009.

[14] W. L. Stone and L. M. Caro-Martinez, "Naturalistic observations of spontaneous communication in autistic children," Journal of Autism and Developmental Disorders, vol. 20, no. 4, pp. 437-453, 1990.

[15] D. R. Beukelman and P. Mirenda, Augmentative and Alternative Communication. Management of Severe Communication Disorders in Children and Adults, Paul H. Brookes Publishing, Baltimore, Md, USA, 1992.

[16] C. Lord, "Commentary: achievements and future directions for intervention research in communication and autism spectrum disorders," Journal of Autism and Developmental Disorders, vol. 30, no. 5, pp. 393-398, 2000.

[17] P. Mirenda, "Autism, augmentative communication, and assistive technology: what do we really know?" Focus on Autism and Other Developmental Disabilities, vol. 16, pp. 141-151, 2001.

[18] B. T. Ogletree and W. E. Harn, "Augmentative and alternative communication for persons with Autism: history, issues and unanswered questions," Focus on Autism and Other Developmental Disabilities, vol. 16, pp. 138-140, 2001.

[19] A. S. Bondy and L. A. Frost, "Mands across the water: a report of the application of the picture-exchange communication system in Peru," The Behavior Analyst, vol. 16, pp. 123-128, 1993.

[20] A. S. Bondy and L. A. Frost, "The picture exchange communication system," Focus on Autistic Behavior, vol. 9, pp. 1-19, 1994.

[21] A. S. Bondy and L. A. Frost, Pictures Worth: PECS and Other Visual Communication Strategies in Autism, Woodbine House, Bethesda, Md, USA, 2002.

[22] J. Boucher and V. Lewis, "Guessing or creating? A reply to Baron-Cohen," British Journal of Developmental Psychology, vol. 8, pp. 205-206, 1990.

[23] E. G. Carr and E. Kologinsky, "Acquisition of sign language by autistic children. II: spontaneity and generalization effects," Journal of Applied Behavior Analysis, vol. 16, no. 3, pp. 297-314, 1983.

[24] M. Carter, "Communicative spontaneity of children with high support needs who use augmentative and alternative communication systems I: classroom spontaneity, mode, and function," Augmentative and Alternative Communication, vol. 19, no. 3, pp. 141-154, 2003.

[25] M. Carter and H.-M. Chiang, "Spontaneity of communication in individuals with autism," Journal of Autism and Developmental Disorders, vol. 38, no. 4, pp. 693-705, 2008.

[26] M. Carter, G. D. Hotchkis, and M. C. Cassar, "Spontaneity of augmentative and alternative communication in persons with intellectual disabilities: critical review," Augmentative and Alternative Communication, vol. 12, no. 2, pp. 97-109, 1996.

[27] M. H. Charlop, L. Schreibman, and M. G. Thibodeau, "Increasing spontaneous verbal responding in autistic children using a time delay procedure," Journal of Applied Behavior Analysis, vol. 18, no. 2, pp. 155-166, 1985.

[28] L. Kanner, "Autistic disturbances of affective contact," Nervous Child, vol. 2, pp. 217-250, 1943.
[29] L. K. Koegel, "Interventions to facilitate communication in autism," Journal of Autism and Developmental Disorders, vol. 30, no. 5, pp. 383-391, 2000.

[30] J. C. Light, B. Roberts, R. Dimarco, and N. Greiner, "Augmentative and alternative communication to support receptive and expressive communication for people with autism," Journal of Communication Disorders, vol. 31, pp. 153-180, 1998.

[31] D. Preston and M. Carter, "A review of the efficacy of the picture exchange communication system intervention," Journal of Autism and Developmental Disorders, vol. 39, no. 10, pp. 14711486, 2009.

[32] J. Riechle and J. Sigafoos, "Establishing spontaneity and generalization," in Implementing Augmentative and Alternative Communication: Strategies For Learners with Severe Disabilities, J. Reichle, J. York, and J. Sigafoos, Eds., pp. 157-192, Brookes, Baltimore, Md, USA, 1991.

[33] D. Cantwell, L. Baker, and M. Rutter, "A comparative study of infantile autism and specific developmental receptive language disorder. IV. Analysis of syntax and language function," Journal of Child Psychology and Psychiatry and Allied Disciplines, vol. 19, no. 4, pp. 351-362, 1978.

[34] K. A. Kroeger and W. M. Nelson III, "A language programme to increase the verbal production of a child dually diagnosed with Down syndrome and autism," Journal of Intellectual Disability Research, vol. 50, no. 2, pp. 101-108, 2006.

[35] M. H. Charlop and L. K. Haymes, "Speech and language acquisition and intervention: behavioural approaches," in Autism in Children and Adults: Etiology, Assessment and Intervention, J. L. Matson, Ed., pp. 213-240, Brooks Cole, Belmont, Calif, USA, 1994.

[36] L. A. Kaczmarek, “Teaching spontaneous language to individuals with severe handicaps: a matrix model," Journal of the Association for Persons with Severe Handicaps, vol. 15, pp. 160169, 1990.

[37] C. Potter and C. Whittaker, Enabling Communication in Children With Autism, Jessica Kingsley, London, UK, 2001.

[38] M. Carter and G. D. Hotchkis, "A conceptual analysis of communicative spontaneity," Journal of Intellectual and Developmental Disability, vol. 27, no. 3, pp. 168-190, 2002.

[39] J. W. Halle, "Teaching language in the natural environment: an analysis of spontaneity," Journal of the Association for Persons with Severe Handicaps, vol. 12, pp. 28-37, 1987.

[40] M. Carter, "Communicative spontaneity of children with high support needs who use augmentative and alternative communication systems II: antecedents and effectiveness of communication," Augmentative and Alternative Communication, vol. 19, no. 3, pp. 155-169, 2003.

[41] C. Kasari, M. Sigman, and N. Yirmiya, "Focused and social attention of autistic children in interactions with familiar and unfamiliar adults: a comparison of autistic, mentally retarded, and normal children," Development and Psychopathology, vol. 5, pp. 403-414, 1993.

[42] P. Warreyn, H. Roeyers, and I. de Groote, "Early social communicative behaviours of preschoolers with austism spectrum disorder during interaction with their mothers," Autism, vol. 9, no. 4, pp. 342-361, 2005.

[43] S. Panerai, L. Ferrante, V. Caputo, and C. Impellizzeri, "Use of structured teaching for treatment of children with autism and severe and profound mental retardation," Education and Training in Mental Retardation and Developmental Disabilities, vol. 33, no. 4, pp. 367-374, 1998. 
[44] National Research Council, Committee on Educational Interventions for Children with Autism, Division of Behavioral and Social Science and Education, Educating Children with Autism, National Academy Press, Washington, DC, USA, 2001.

[45] J. Houghton, G. J. Bronicki, and D. Guess, "Opportunities to express preferences and make choices among students with severe disabilities in classroom settings," Journal of the Association for Persons with Severe Handicaps, vol. 12, pp. 18-27, 1987.

[46] D. Keen, J. Sigafoos, and G. Woodyatt, “Teacher responses to the communicative attempts of children with autism," Journal of Developmental and Physical Disabilities, vol. 17, no. 1, pp. 1933, 2005.

[47] S. F. Warren, P. J. Yoder, G. E. Gazdag, K. Kim, and H. A. Jones, "Facilitating prelinguistic communication skills in young children with developmental delay," Journal of Speech and Hearing Research, vol. 36, no. 1, pp. 83-97, 1993.

[48] P. Yoder, S. Warren, R. McCathren, and S. Leew, "Does adult responsivity to child behavior facilitate communication development?" in Transitions in Prelinguistic Communication, A. Wetherby, S. Warren, and J. Reichele, Eds., vol. 7, pp. 39-58, Brookes, Baltimore, Md, USA, 1998.

[49] H.-M. Chiang, "Expressive communication of children with autism: the use of challenging behaviour," Journal of Intellectual Disability Research, vol. 52, no. 11, pp. 966-972, 2008.

[50] B. Holden and J. P. Gitlesen, "A total population study of challenging behaviour in the county of Hedmark, Norway: prevalence, and risk markers," Research in Developmental Disabilities, vol. 27, no. 4, pp. 456-465, 2006.

[51] G. H. Murphy, J. Beadle-Brown, L. Wing, J. Gould, A. Shah, and N. Holmes, "Chronicity of challenging behaviours in people with severe intellectual disabilities and/or autism: a total population sample," Journal of Autism and Developmental Disorders, vol. 35, no. 4, pp. 405-418, 2005.

[52] R. M. Reese, D. M. Richman, J. M. Belmont, and P. Morse, "Functional characteristics of disruptive behavior in developmentally disabled children with and without autism," Journal of Autism and Developmental Disorders, vol. 35, no. 4, pp. 419-428, 2005.

[53] V. M. Durand and E. G. Carr, "Functional communication training to reduce challenging behavior: maintenance and application in new settings," Journal of Applied Behavior Analysis, vol. 24, no. 2, pp. 251-264, 1991.

[54] C. S. Englert, "Measuring special education teacher effectiveness," Exceptional Children, vol. 50, pp. 247-254, 1983.

[55] C. S. Englert, "Measuring teacher effectiveness from the teacher," Focus on Exceptional Children, vol. 17, pp. 1-15, 1984.

[56] K. A. Quill, Teaching Children with Autism: Strategies to Enhance Communication and Socialization, Delmar Publishing, New York, NY, USA, 1995.

[57] J. Sigafoos, J. Reichle, S. Doss, K. Hall, and L. Pettitt, “'Spontaneous' transfer of stimulus control from tact to mand contingencies," Research in Developmental Disabilities, vol. 11, no. 2, pp. 165-176, 1990.

[58] H. Goldstein, "Communication intervention for children with Autism: a review of treatment efficacy," Journal of Autism and Developmental Disorders, vol. 32, no. 5, pp. 373-396, 2002.

[59] M. Hauck, D. Fein, L. Waterhouse, and C. Feinstein, "Social initiations by autistic children to adults and other children," Journal of Autism and Developmental Disorders, vol. 25, no. 6, pp. 579-595, 1995. 

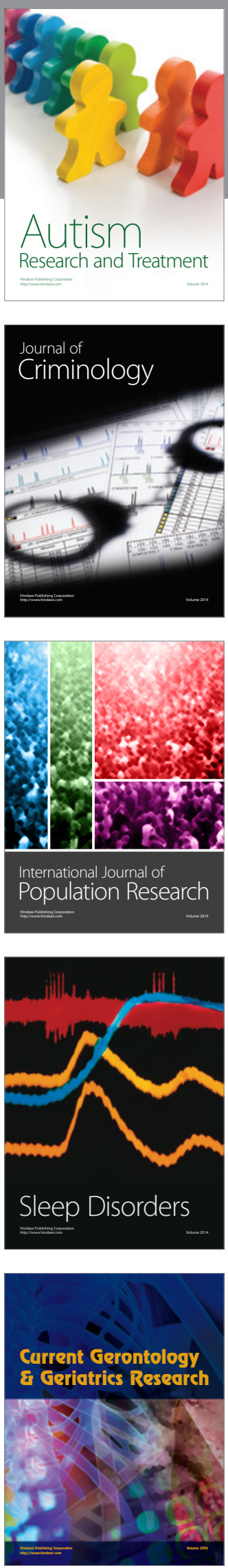
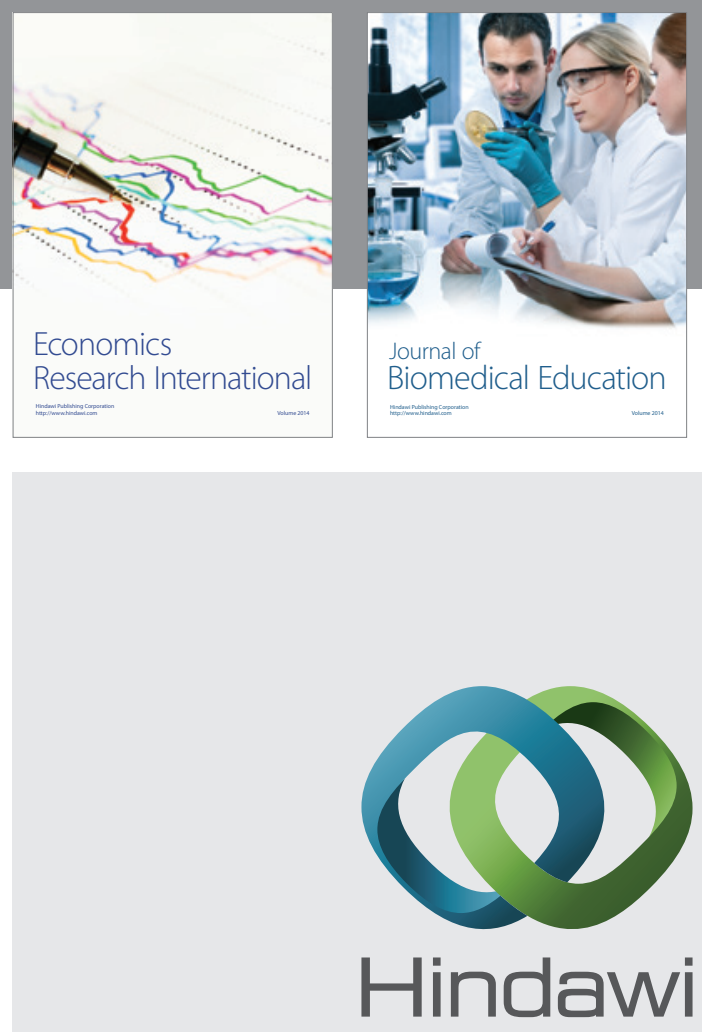

Submit your manuscripts at

http://www.hindawi.com
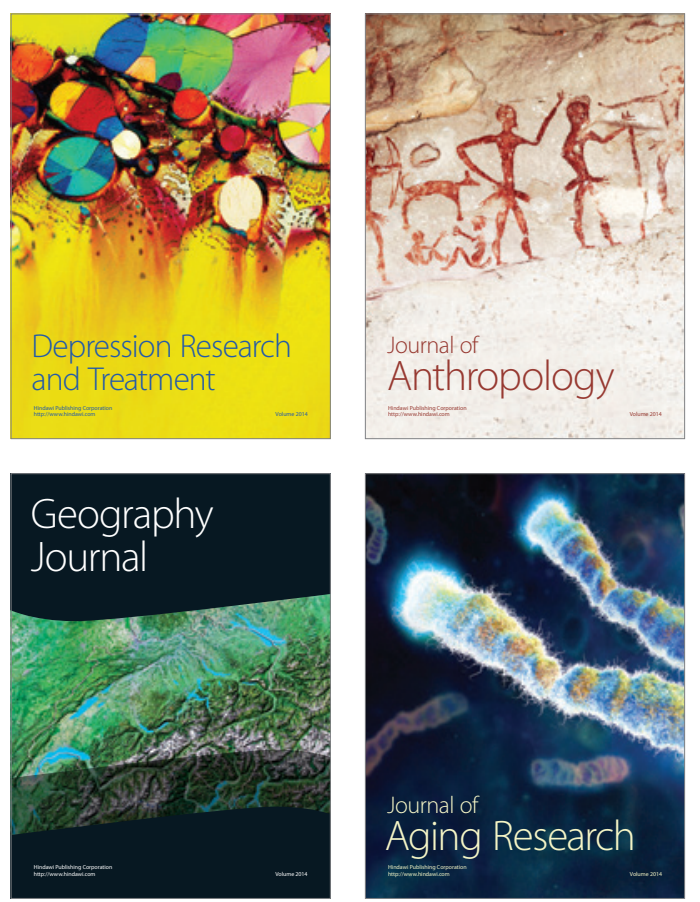
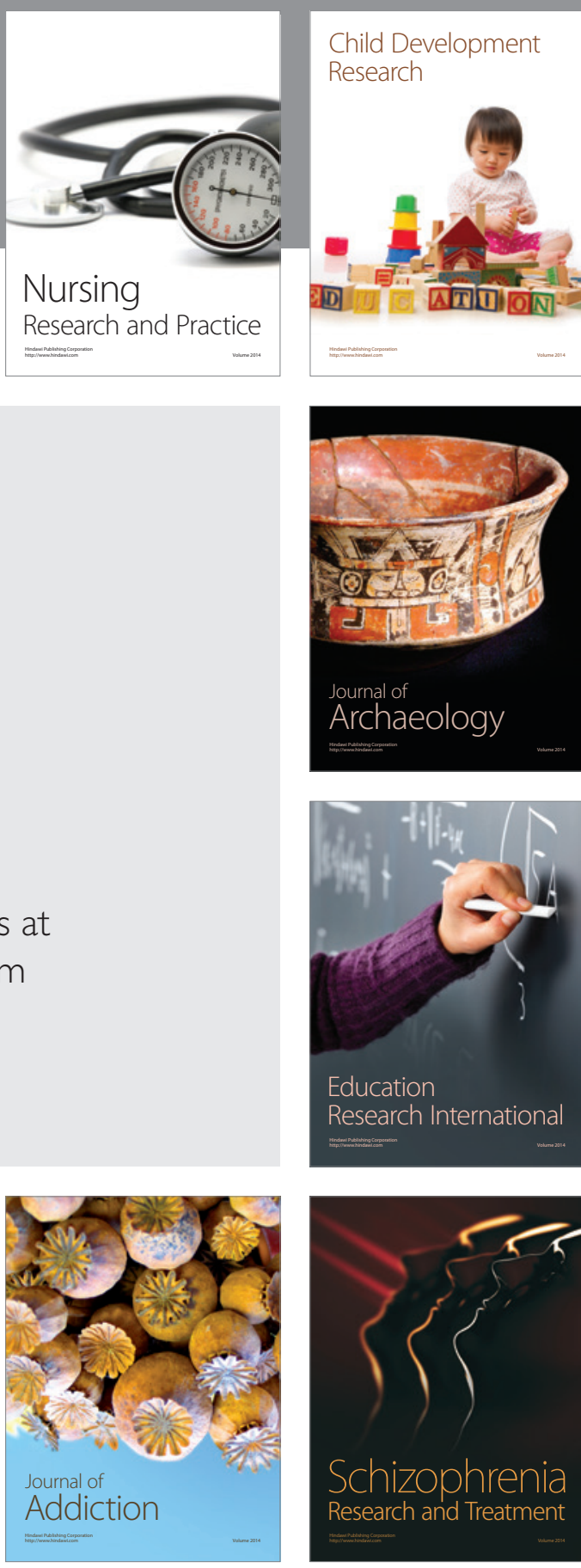

(D)
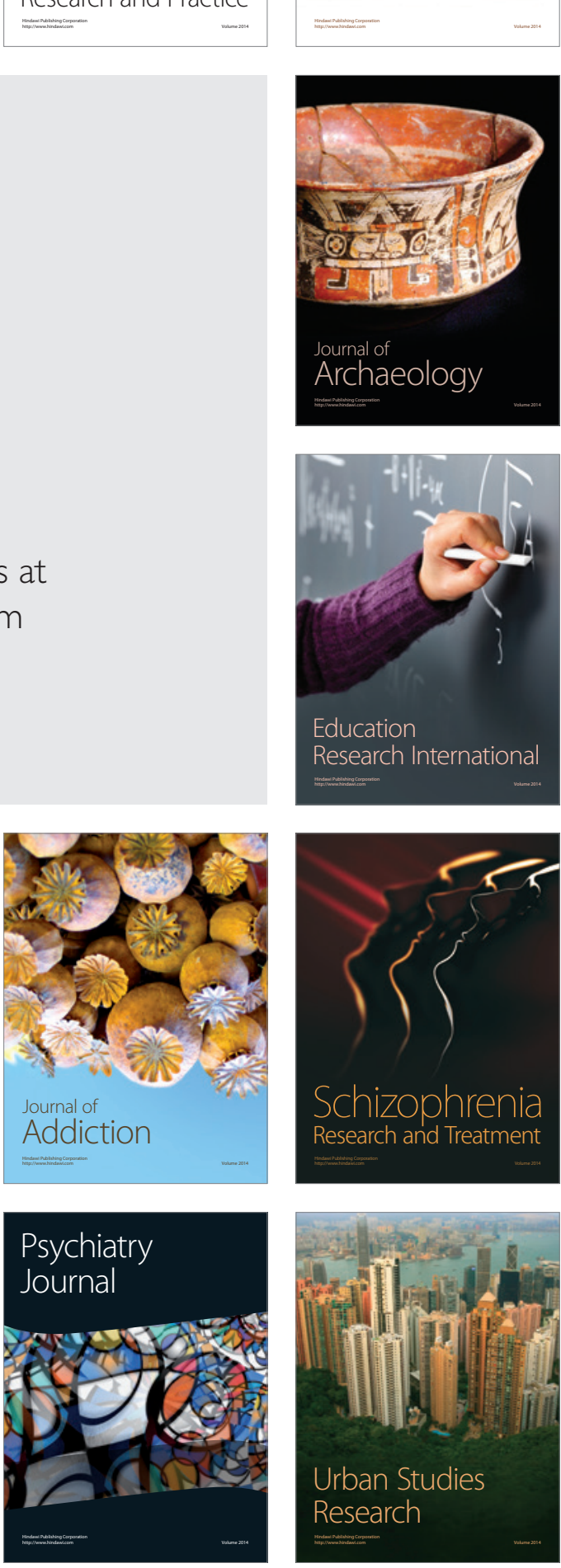